\title{
Bodies of Images: Art Education After the Internet
}

\author{
Konstanze Schütze
}

Images are complex accumulations, which in their doings are capable of shaping the present. We need to explore them as the hyper-active entities they are. (Schütze, 2020)

\section{The Postdigital Condition}

The slightly provocative after the internet in the title of this chapter stems from a publication on contemporary art production and curating by Omar Kholeif (Kholeif 2014). After the internet situates the following considerations within a reading of the internet as the predominant infrastructure of the present. In this context, the preposition after marks a state that encompasses the extensive effects of a revolution in media technology and communication. This idea will be built upon in this chapter. Piotr Czerski (2012) described the internet as something not so external to reality, but inseparable from it. By framing this layer as "an invisible yet constantly present layer intertwined with the physical environment" (para.

\footnotetext{
K. Schütze $(\otimes)$

University of Cologne, Cologne, Germany

e-mail: k.schuetze@uni-koeln.de

(C) The Author(s) 2021

K. Tavin et al. (eds.), Post-Digital, Post-Internet Art and Education, Palgrave Studies in Educational Futures, https://doi.org/10.1007/978-3-030-73770-2_5
} 
4), Czerski offered a handy description for the fundamental changes in the contours of our experience in an internet-state-of-mind (Müller, 2011) or culture of digitality (Stalder, 2017). ${ }^{1}$ The invisible socio-technological layer, which seems genuinely interwoven with the physical realm, has expanded into a sphere and has formed an ordering principle that goes far beyond the accumulation of devices, cables, and signals. Moreover, it is increasingly invisible (para. 4) and experienced in its effects only and must be interrogated as such.

What we are dealing with is a shift so profound that it can only be outlined when observed in close relation to its anchor points (Schütze, $2018) .^{2}$ To translate this shift into more technical terms, media educator and educational theorist Benjamin Jörissen (2017) names three central areas: software, hardware, and infrastructure. The level of software encompasses apps and programs; hardware includes devices and technical components; while the level of infrastructure encompasses the connections and relationships between all human and non-human agents, including the created network frequencies and bandwidths. Together, "these structural spheres represent the performative, symbolic, connective, and material aspects of digitality" (Jörissen, 2017, para. 10, transl. by author) interlaced in so many complex interrelations, and with farreaching technological, social, and political effects. These transformed conditions have led to transformed demands, which in turn bring forth transformed cultural practices and vice versa. Taking into account that the latter plays a central role both in the reflection and production of art, one can safely assume that the resulting feedback effect is relevant for art education as well.

In this chapter, I present a series of thought experiments for a differentiated exploration of what one might casually call the image. Basing on three major theoretical concepts (meme theory, object-oriented ontology, and network effects), images will be reintroduced as entities embedded in complex structural realities that are both driving and driven forces of culture. In this endeavor, they will be rendered as bodies compiled from versions of themselves (bodies of images), explored embedded in dissemination processes (memeplexes), and hence contoured as highly effective structures with sophisticated potential for transformation (image objects). With this $r e$-interrogation of the image is the suggestion of reading of images as entities that actively, or inactively, form structural assemblages and maintain energetic human and non-human constellations. At the 
close of the exploration, a professional habitus is sketched in which art educators are experts for image relations.

\section{The Image as Dominating Cultural Entity}

Unsurprisingly, one of the most central nodes within the core of this exploration seems to be the image itself. As a traditional multiplier of ideas, visual appearances seem to structure almost every process of social, economic, and political life online and offline alike. One way of contouring the mentioned condition would be taking a look at the involved quantities and their effects (Kurbjuhn, 2014). In 2015, users uploaded 657 billion images to the internet (Rosa, 2015). Given these numbers and the growing metaphors around a noticed dominance of the visual, one can recognize an essential structural shift in both online and offline images and their biotopes. More recently, even everyday language accredits a particular agency to images as entities. At times, they have been attributed with the potential to seduce and overpower human thought despite their inanimate nature. As internet memes, images seem to be in their most agile form and their most omnipresent. Images as memes are at once considered entertainers, agitators, catalysts, and even essential commentators of transcultural exchange. Visual information supports a diversity of processes economically, politically, and culturally, which leads to merely incomprehensible amounts of data waiting to be realized on screen and cast into visual highways. Hence, it is no surprise that their rank as passive objects has been repealed, and they've been taken to task primarily for their part in consumer choices and election results (see, for example, Pepe the Frog in the 2016 US elections). In this exploration, I attempt a logically consistent account of these phenomena in which images are conceived and analyzed as dominating cultural entities (German original: geschäftsführende kulturelle Entitäten). The term draws on the description of a next society (nächste Gesellschaft) by sociologist and cultural theorist Dirk Baecker (2011), who has stated, "The next art is the art of the next society," (Meyer, 2014, p. 218) and this next society is "based on the computer as the leading media technology" (p. 218). This observation was introduced into the art education theory by Torsten Meyer (2014) and seems on point and further sharpens the questions at hand for this inquiry: how are images and visual structures organized, and which effects promote their circulation and lead to the capitulating effects of agency embedded in the visual? How can one cease 
to imagine their overpowering circulatory potential and their dynamic logics of distribution if images dominate in a cultural and even political sense? Furthermore, which consequences and challenges do these changes entail in education?

\section{Diffusion Processes and Virals}

In the omnipresent game of winning attention which structures the present, the image is a winner and a loser at the same time. Deeply entangled in the mesh of the present conditions, images are fleeting appearances that command short intervals of attention. Hence, the individual image is relentlessly subjected to regimes of attention and can assert its presence only for a brief moment. Communications scholar Limor Shifman has identified active diffusion processes which facilitate the viral dissemination of these agile entities. Through them, messages, keywords, videos, and images spread from person to person with high speed and broad reach, she summarizes with reference to the internet: "More than any previous medium, the internet has the technical capabilities for global meme diffusion" (Thelwall \& Shifman, 2009, p. 2567; Berger \& Milamn, 2012). In their research of the effects in Going Viral, Karine Nahon and Jeff Hemsley (2013), two media scholars, offered an overview of the critical elements in viral phenomena. According to the authors, so-called gatekeepers (individuals or groups of users with a rather strong impact on their network), are essential for the dissemination and diffusion between networks, and viral processes cannot gain ground without their selection and support (Nahon \& Hemsley, 2013). Each viral entity is subsequently the product of gatekeeping activities and reliant on a network of larger interest groups held by the gatekeepers (Chielens \& Heylighen, 2009). The sustained hype over cat content and the diversity of iconic new memes are a daily testament to this content propagation process.

Viral content and strategies cannot always be thought of as being positive for society only; they can also have far-reaching adverse effects. One such case is the growing phenomenon of so-called social engineering, which in its original meaning, encompasses forms of psychological manipulation in addition to creative methods of social research. Recently, the set of techniques came to the fore when charges were made against the company Cambridge Analytica. They were accused of at least supporting, if not downright enabling, the rigging of elections via meme direction and complex alternative news cycles. Such social manipulation, that 
is, deployment of viral campaigns, can have far-reaching effects, especially when paired with image networks and accumulations of successful memes embedded in more complex, and often unnoticed, meme engineering (Keller 2017; Seemann, 2014). Cultural studies scholar and blogger Michael Seemann describes the phenomenon of Kontrollverlust (loss of control over data) as a result of involuntary subjugation to socio-technological effects and power structures. He points to the WikiLeaks exposés and their rapid dissemination as an example: "Within two days, 750 'mirrors' had popped up on other computers connected to the internet [and] a few weeks later, the number had grown to 1,426" (Seemann, 2014, p. 28). Given the exponentially increasing volume of data and available storage in addition to faster copying rates, the information highway has indeed become a one-way street when it comes to personal control. Seemann furthermore deduced that information could spiral beyond any possible control. Within these omniscient and dominating technological infrastructures, knowledge then simply prevails in the ability to intelligently link data despite its unbearable volume.

\section{Habits And Modes of Reception}

Having outlined the conceptual background for a logic after the internet and having introduced the image as an entity within various reciprocal relations, rather than an object at our disposal, the next vignette will focus on providing a few more anchor points directly connected to the structural aspects of the image. The first line of thought in this part of the investigation concerns the transformation in our reception habits. It demands an inventory of the tools and concepts we use to deal with images from an interdisciplinary perspective. This trail of thought leads me back to my favorite example, the Mona Lisa, whose original is on display in the painting collection of the Louvre in Paris, more specifically la Salle de la Joconde, and has at least 22.8 million avatars, versions, and copies online, as well as a broad and almost universal transcultural reputation. ${ }^{3}$ Given this fame and the omnipresence of its depictions online and offline, the Mona Lisa nearly demands to be constantly reproduced and written about-even when the creator has no knowledge of the original context.

The example of the Mona Lisa's body of distributed images directs the focus of my inquiry toward the complexified relationship of the original with its copies, versions, adaptations, and derivatives. We are no 
longer dealing with an individual sovereign image bound by the canvas on which it lies, but rather face an accumulation of images disseminated across the most disparate platforms and circulating through the analog and digital worlds. The circulating avatars of classic artworks and transcultural artifacts are certainly worth a more detailed exploration in terms of their context and sets of features in correlation with the effects of their circulation.

\section{Object Orientation: Networks and Image Objects}

The image made itself independent and gained an agency which is hard to contour and fix, even in its dynamics. The resulting understanding of an agile entity with a specific situatedness (see Haraway, 1988)-like the image - draws on contemporary debates in the philosophical areas of New Materialism (Coole \& Frost, 2010; Gabriel, 2016) and Speculative Realism (Harman, 2010; Avanessian, 2013). The reflections of an early Object-Oriented Ontology (Bryant, 2011; Harman, 2016) draw attention to the essence and the being of things simultaneously. The version of object orientation I am interested in-while focusing on image structures-builds on an Actor-Network Theory that examines the interplay between human and non-human entities. Actor-Network Theory (Latour, 1986; Latour, 2005) considers objects as active entities in reciprocal relationships with human and non-human actors within the specific condition of the present (see Haraway, 2016; Braidotti, 2019).

Levi R. Bryant (2011) elaborated on this concept. To him, objects ought to be understood less as individual actors than active entities with individual properties and agencies. In this logic, objects result from at least two states of activity, which can furthermore intersect: (1) actuality (realized aspects) and (2) virtuality (potential aspects). Graham Harman (2016) draws even further beyond these readings of objects as having agency and renders different elements (entities) in relation to others in joined ventures. These entities in relationships could be labeled "compound objects" (Harman, 2016). His argument for such an understanding of objects is that the concrete and cumulative effects of these objects go far beyond the impact of the individual partaking entities-they are infrastructural. Harman hence uses the term object to describe a structure and mode of operation rather than referring to discrete things or solid matters. The objects, as proposed by Harman, are 
the products of human and non-human actors embedded in their infrastructures and the logics; they share agencies and effects across vast spatial and temporal distances through catalyzing (symbiotic) connections and relations (Harman, 2016).

The following thought experiment hence shifts our understanding of the image toward a more structural understanding as a group of entities in relation (compound objects). It even opens up a rather vast potential for a reorganization of the contours of the image in the post-internet research on it. Following Graham Harman's argument, a reading of images as entities seems useful for the rendering of the active dynamics. Considered in this way, images actively or inactively form structural assemblages with other entities and often participate in a shared function with them. Moreover, to sharpen the point here, images are "units in action" organized across spatial and temporal distances, which develop significant and collective impact. In coalition with other entities, they may even produce a cumulative effect. With this in mind, the following vignette will offer some approaches for examining these structural entities, their assemblages, and their relations (together forming the image object). This will place some considerations on a yet-to-be-developed mode of discussing distributed images in the present and their entanglements (Barad, 2007). Consequently, people today are witnessing how images emerge and how they organize in alliances with individual entities when producing their unique effects.

In the process, these formed compound objects (more specifically maybe image objects) gather their impact from the entirety of all the relations and potentials of their participating entities. One must, of course, ask whether the term image object would be suitable for what we have been labeling so bluntly as images in art history for such a long time. Indeed, what we are now investigating as images proves structurally very similar to what Harman designated compound objects (2016)—derived mostly from the agency of the image itself. ${ }^{4}$ The following part of this exploration will add to this interrogation of the image and further summarize compact concepts around the structural novelty in the realm of the digital.

\section{BODIES OF IMAGES}

The metaphor of a sea of data (Steyerl, 2016) serves as a powerful vignette of the complexity involved with a mesh of conditions. This visualization 
renders a vastness that is made up of integral parts and visually captures the sheer infinity of collected data. Individual images are thought of as results of their relations to all other images and imagined as drops of water in a vast sea. Hence, versions of images that are reproduced and disseminated independently of their original, and without any memory of their provenance tend to produce a quasi-autonomous mass with specific laws and effects beyond human control. Comparable to natural phenomena, they exceed the limitations of our tools and techniques and organize into diverse and agile accumulations of superimposed and disseminated images. In their effects, they are similar to accumulations of spontaneously condensing water droplets and might be imagined as towering and charged cumulonimbus clouds, which can occasionally discharge in the form of thunderstorms (or in this case, e.g., viral shitstorms), almost of their own accord, as quasi-autonomous natural phenomena. Quantitative and network-theoretical investigations are pending, yet necessary to substantiate these pictures with numbers and data (Seemann, 2014). A preliminary note for further research: images not only organize into compound objects, they also organize into diverse accumulations with other entities beyond any direct control.

Using this thought as a backdrop for another metaphoric elaboration around the image, the Mona Lisa is again referenced. The original has millions of versions that it interacts with symbiotically and competitively. In analogy to an actual body of water, which builds on the idea that water is a divisible body that can still be whole without abandoning the individual (the drops, liters, and milliliters), we might also come to speak of bodies of images. In the attempt of contouring what we call the Mona Lisa for example, the entirety of all versions and entities of the painting by Leonardo Da Vinci (online and offline alike), could be described as an object with shared properties (and presences) and metaphorically be labeled the body of images of the well-known Mona Lisa. Consequently, connecting these lines of thought, the accumulation of versions or variants of an image form a higher degree of momentum than the entities involved would be able to achieve on their own. Moreover, these bodies of images (the Mona Lisa and other bodies alike) follow their own laws and dynamics.

Moreover, even if they remained inactive at the moment, or in some aspects hidden or invisible, as Harman (2009) deems true for compound objects, they can be effective and hence obtain a form of infrastructural agency. Activity and inactivity are thus not limited to the perceivable parts 
of reality, therefore entities and their relations are generally regarded as units in action or even "compound objects" (Harman, 2009, p. 214). My preliminary conclusion from an object-oriented approach renders images into entities, which are best explored as units in action with a strong inherent tendency to forming highly effective compound objects that highly benefit from the effects of their collectives (visible or not).

\section{Meme Theory: Image Complexes}

Without sending the already interrogated aspects away, the following paragraphs will invest in another theoretical perspective. Another way of approaching the structure and logic of the image is the research on their memetic effects. Sharing, remixing, copying, \& pasting are now integral parts of everyday digital life. These standard practices, which so decisively determine content and impact on the internet, are also increasingly evident in non-digital or offline ${ }^{5}$ forms of expression. For this reason alone, it is important to observe and analyze practices and effects in both online and offline contexts. Shifman spoke of the "hypermemetic nature of contemporary culture" (Shifman, 2014a, p. 24). ${ }^{6}$ Before the internet, the dissemination and thus the extent of original memes was limited. Shifman points out that "each individual was exposed to a very limited number of memetic manifestations," however, today, we face innumerable "memetic manifestations" and material with high "potential for dissemination" (Shifman, 2014a, p. 28). On a larger scale, these effects cumulatively produce their specific logic of modifying, copying, sharing, and disseminating, which Shifman describes as the "hypermemetic logic" of the present (Shifman 2014b, p. 28). For the question of what images and their transformed properties are, these are important considerations that could certainly be expanded.

However, in contrast to the analog dissemination of cultural entities, the speed and extent of dissemination maneuvers on the internet can now be read and understood in a completely different way and thus can at least be described and contoured as phenomena, despite whatever gaps we may face in explaining their genesis and nature. Yet another aspect of Shifman's approach is of integral importance for the investigation of contemporary images: the relationship of memes to one another, which she draws from Susan Blackmore's explorations of Dawkin's concept. Blackmore sees each meme as one entity among many, which form "co-adapted meme complexes" (Blackmore, 1999, p. 51; Shifman, 2014a, p. 10; Dawkins, 
1999). Co-adapted meme complexes are systems of individual memes that are semantically or organizationally linked and mutually reinforce each other. Blackmore shows that each meme is part of an environment, and thus part of other potential memes of the same environmental background. So-called "selected memes," i.e., successful memes that stand out or assert themselves against a common background of other memes, cooperate and spread more widely and sustainedly. Blackmore calls an effective grouping a "memeplex" (Blackmore, 1999, p. 19).

Furthermore, successful entities seem to profit from mutual advantages when supported by other successful memes. This effect leads to highly dynamic communication structures around the image and its accumulations. This, in turn, connects back to strategies of memetic engineering and the idea that content can be modulated into successful content online, such as internet memes. With the emergence of companies like Cambridge Analytica and the rising certainty that internet memes spread ideas faster than other media, the slipstream effects of particularly dissemination-friendly content has reached a new level. This has strong implications for education. Especially, given the risks posed by combinations of phenomena such as fake news and deep fakes, the general memetic logic of the present asks for far more structured concepts in confronting the loss of control coming with it. As these innovations in more political environments relate to educational and political questions, the present investigation is intended to offer a starting point for a theoretical framework surrounding the implications for education.

The concept of a meme certainly has a lot to offer as an analytical tool for interrogation of the image in this endeavor surrounded by the current mesh of conditions. Consistently assessing the image as visual entities in circulation, addressed as memes-following the definitions of meme by Dawkins (1976) and Hull (1982)—within specific co-occurring conditions is a handy basis for a deeper understanding of their logic of dissemination and effectiveness. Methodologically speaking, it seems clear that one must dissect the image-like the meme-into the factors of its effectiveness to build on them for analysis. For the present exploration, more generally applying the concept of memeplexes (Blackmore, 1999; Shifman, 2012) to the organizational structures of images and thinking through their implications in art and artworks seems a very logical next step for the research of the image in its relations. A systematic empirical or network-theoretical series of studies on some of the common patterns 
associated with dissemination of visual and non-visual appearances in the arts would be a good start for this endeavor.

\section{Relational Entities ANd Doing Images}

The attempts thus far at describing the structural conditions for the image offer a relational understanding of the image itself. The introduced approaches focus on the relationships that individual images maintain and entertain with other images. At the same time, this approach to images and their relations also considers the interactions of images with other human and non-human entities in specific structural accumulations (Braidotti \& Hlavajova, 2018; Haraway, 2016). The dissolution of this parting line situates the image anew, separated from its materiality (and abstracted to a large extent), as a complex entity within the present. It furthermore allows an investigation of the relations without the ballast of the logic of a unique cultural object to which artworks often fall prey. Thus, it seems even more necessary to develop a somewhat unwieldy yet precise formula for the image. While the suggested explanatory models already sketch a helpful matrix for discussing the image of the present, it seems unwise to further pursue broad and interdisciplinary excursions on the image at this point (these are provided in Schütze, 2020). Instead, I would like to focus on the doings with images of a culture deeply embedded in visual culture and finally draw attention to two examples in application. These examples are mentioned to hint at the necessity to understand the complex relations of the image in dissemination and to highlight the extended network of many actors, aspects, and approaches which predominantly are at once active.

The first of the two applications follow the work of art historian and cultural studies scholar Philipp Ekardt, whose approach-drawing on the artists' group Bernadette Corporation as an example-is useful for the discussion of contemporary images. The central point here is the comparative approach to images, which focuses on professed "image milieus" (Ekardt, 2014, p. 89). The procedure can be described as: images are examined in contrast to other images of their time (synchronouslysimultaneously), against their technical and social background, as cultural manifestations. Additionally, they are observed and analyzed embedded in their historical-technical conditions across times (diachronically-between times). Using the example of the Mona Lisa, one may ask: which images 
surrounded the Mona Lisa at the time of its creation or during its reception (simultaneous) and how can it be understood embedded in groups of images within selected image milieus (diachronic)? Investigating this is not only the task of art-historical analysis, it is a challenge for art education, which is creating experts on the relations surrounding images. In contrast this approach is the work of sociologist Regulia Valérie Burri regarding the concept of image in the present. With her concept of "doing images" (Burri, 2008, p. 346), she considered the essential imageconstituting aspect of working with the image: the actions performed with images make the image. Here, too, the Mona Lisa is a good example. Photographing, adapting, and sharing the Mona Lisa make it the most famous work of art over and over again and determines its self-renewing, pervasive familiarity. The specific interaction with the artifact thus constitutes it in the first place. It contributes avatar by avatar, version by version, to the Mona Lisa's particular temporary or permanent image milieu.

\section{Conclusions: Understanding Image Complexes}

It becomes increasingly impossible to grasp the full extent of the induced transformations and their far-reaching implications. Given the fact that the present infrastructures are entertained by networked communication and algorithmic structures, the image has transformed so fundamentally in structure and surface that categorical descriptions prove increasingly difficult (see Stalder, 2017). As complex accumulations, images appear in various - and even intersecting-forms. Between their digital and analog aspects, they occur visually, non-visually, or ephemerally at times. They constitute units in action and hence entertain far-reaching relationships with one another. Images even seem to increase their effectiveness when they organize themselves into (or are organizing towards) diverse accumulations with other entities. Images benefit strongly from networking effects. Gaining an understanding of the image demands a much deeper and more complex interrogation into its techno-social condition and requires structural and discursive knowledge about images in complex constellations in general.

This chapter aimed to form a foundation for such a conversation about the educational possibilities as a first step. Encountering images in their complex structural logic and gaining the most precise knowledge possible of the outlined structures, dynamics, dependencies, and doings enrooted in the image, will be one of the most meaningful explorations and learning 
grounds for contemporary art education. As an art educator, one needs to outline the transformed structures of visuality and imagery in the present and question one's own approaches to the complexity of the present condition. In order to help shape the future, despite the difficulties, one needs to recover implicit (or concealed) knowledge about its complexity. Informed handling of visual and non-visual structures is the basis of any productive relationship with the present mesh of conditions. Starting from the image simply makes sense.

Moreover, the proposed conceptualization of the image after the internet at least indirectly imposes a need for rethinking some of the most traditional concepts of educational theory and adds essential material to the long overdue conversation in the field (see Klein et. al., 2017; Leeker, 2018). One such aspect would be the subject of education, which has been subjected to transformation and seems to have transgressed even further within the mesh of current conditions to dissolve into complex structures (Jörissen \& Meyer, 2015). Others are found in the very current and profound $r e$-evaluation of active hegemonies of power and structures of colonization that need interrogation from a diversity of perspectives and practices. Consequently, this means that there is a need to invest tools, knowledge, abilities, and professional material far beyond what the practice suggests at the moment in seeking to understand works of art as complex code embedded in active visual and non-visual structures. When allowed, images can be trusted allies in this attempt of understanding the present. However, they need to be explored as the hyper-active entities embedded in structures that they are, rather than as passive, solid objects obedient to our actions.

\section{Notes}

1. Here, I'd like to thank Torsten Meyer for pointing out the Web Kids Manifesto (2012).

2. See, for example, the analysis of the "Postdigital Condition" in my dissertation (Schütze, 2020). This paraphrase draws on Jean-François Lyotard's account of The Postmodern Condition (1979/1984). He outlines a society that accepted the social, political, technological, and economic transformations brought forth by modernity as self-evident, without assessing the reasons for these transformations (see also Jameson, 1990).

3. On January 4, 2018 (CET), googling the term "Mona Lisa" yielded $25,800,000$ results using the standard settings from the Berlin location. 
4. To narrow this essential thought down, I would like to divert into a question: How does the Mona Lisa relate to Pizza Hut's advertisements of the same entity; and what can we learn from it as spectators and as target groups of these choreographed relations?

5. Here, the term non-digital refers to contemporary and historical processes of creation that do not primarily generate digital processes or results, for example, performances or woodcut printing. Similarly, the term offline isn't meant to suggest that it is somehow possible to switch off or otherwise leave the internet. Instead, it describes a polar opposite to phenomena that are entirely determined by the logic of digitization.

6. The attractiveness and dissemination of some online phenomena also have interesting offline effects. One such example would be the 2015-2016 popularity of the Ice Bucket Challenge.

\section{REFERENCES}

Arendt, H. (1968). Zwischen Vergangenheit und Zukunft. Piper: München, Edition 4., 2012.

Avanessian, A. (Ed.). (2013). Realismus Jetzt: Spekulative Philosophie und Metaphysik für das 21. Jahrhundert. Merve.

Baecker, D. (2011). Studien zur nächsten Gesellschaft. Suhrkamp (SuhrkampTaschenbuch Wissenschaft).

Barad, K. (2007). Meeting the universe halfway. Quantum physics and the entanglement of matter and meaning. Durham University Press.

Berger, J., \& Milkamn, K. (2012). What makes online content viral? Journal of Marketing Research, 49(2), 192-205.

Blackmore, S. (1999). The meme machine. Oxford University Press.

Bourriaud, N. (2002). Postproduction. Lukas \& Sternberg.

Braidotti, R. (2019). Posthuman knowledge. Polity Press.

Braidotti, R., \& Hlavajova, M. (Eds.) (2018). Posthuman glossary. Bloomsbury. Bryant, L. R. (2011). Democracy of objects. University of Michigan Library.

Burri, V. R. (2008). Doing Images. Zur Praxis medizinischer Bilder. Transcript.

Cerzki, P. (2012). We the Web Kids Manifesto. en.wikisource.org/wiki/We,_the_Web_Kids.

Chielens, K., \& Heylighen, F. (2009). Cultural evolution and memetics. In R. Meyers (Ed.), Encyclopedia of complexity and system science (pp. 3205-3220). Springer.

Coole, D., \& Frost, S. (2010). Introducing the NewMaterialisms. In: D. Coole \& S. Frost NewMaterialisms: Ontology, agency and politics (pp. 1-43). Duke University Press.

Dawkins, R. (1976). Das egoistische Gen (engl. Orig.: The Selfish Gene). Springer, 1978. 
Dawkins, R. (1999). Foreword. In S. Blackmore (Ed.), The meme machine. Oxford.

Dolphijn, R., \& van der Tuin, I. (2012). New materialism: Interviews \& cartographies. Michigan Publishing, University of Michigan Library. http:// quod.lib.umich.edu/o/ohp/11515701.0001.001.

Ekardt, P. (2014). In defence of styling. Bild Vs. Kunst. Texte Zur Kunst, 24(95), 79-91.

Gabriel, M. (2016). Sinn und Existenz. Eine realistische Ontologie. Suhrkamp.

Haraway, D. (1988). Situated knowledge: The science question in feminism and the privilege of partial perspective. Feminist Studies, 14(3), 575-599.

Haraway, D. (2016). Staying with the trouble: Making Kin in the Chthulucene. Duke University Press.

Harman, G. (2009). Prince of networks: Latour and the metaphysics. Re-press.

Harman, G. (2010). Towards speculative realism: Essays and lectures. Zero Books. Harman, G. (2016). Immaterialism: Objects and social theory. Polity.

Hull, D. L. (1982). The naked meme. In H. C. Plotkin (Ed.), Learning development and culture, essays in evolutionary epistemology. John Wiley and Sons.

Jameson, F. (1990). Postmodernism, or, the cultural logic of late capitalism. Duke University Press.

Jörissen, B. (2017). Subjektivation und ästhetische Freiheit in der post-digitalen Kultur. Kulturelle Bildung Online. https://www.kubi-online.de/artikel/sub jektivation-aesthetische-freiheit-post-digitalen-kultur.

Jörissen, B., \& Meyer, T. (Eds.). (2015). Subjekt Medium Bildung. Medienbildung und Gesellschaft (Vol. 28). Wiesbaden.

Keller, D. (2017). Lecture: The Basilisk. Spike Art Magazine. https://www.you tube.com/watch? $=721$ XhxAHoUI.

Kholeif, O. (2014). You are here: Art after the internet. Cornerhouse.

Klein, K., Kolb, G., Meyer, T., Schütze, K., \& Zahn, M. (2020). Post-internet arts education. In Arts education in transition. kopaed.

Kurbjuhn, C. (2014). Kontur. Geschichte einer ästhetischen Denkfigur. De Gruyter.

Latour, B. (1986). On actor-network-theory. Soziale Welt, 47(4), 369-381.

Latour, B. (2005). Reassembling the social-An introduction to ANT. Journal of Chemical Information and Modeling. https://doi.org/10.1017/cbo978110 7415324.004.

Leeker, M. (2018). (Ästhetische) Vermittlung 2.0. Von Kunst-/Vermittlung und Kritik in digitalen Kulturen. In A. Sabisch, T. Meyer, H. Lüber, \& E. Sturm (Eds.), Kunstpädagogische Positionen (Vol. 40). Hamburg: Universitätsdruckerei.

Lyotard, J. F. (1984). The postmodern condition: A report on knowledge. University of Minnesota Press. 
Meyer, T. (2013). Next art education. Erste Befunde. In T. Meyer \& J. Hedinger (Eds.), What's next? Kunst nach der Krise (pp. 377-384). Kadmos.

Meyer, T. (2014). Next art education. 9 essential theses. In T. Meyer \& G. Kolb (Eds.), What's next? (p. 218). kopaed. http://whtsnxt.net/245.

Müller, D. (2011). Für eine Handvoll JPGs. Tumblerismus und der Internet State of Mind unter die Lupe genommen. In De:Bug. http://de-bug.de/ mag/fur-eine-handvoll-jpgs/.

Nahon, K., \& Hemsley, J. (2013). Going Viral. Polity.

Rosa, E. (2015). How Many photographs of you are out there in the world? The Atlantic. https://www.theatlantic.com/technology/archive/2015/11/howmany-photographs-of-you-are-out-there-in-the-world/413389/.

Schütze, K. (2018). Moving beyond: Bodies of images in spekulativer Zeitlichkeit. In D. Schumacher-Chilla \& N. Ismail (Eds.), Be Aware. Mehr als Gegenwart in der zeitgenössischen Kunst (pp. 75-89). Oberhausen: Athena.

Schütze, K. (2020). Bildlichkeit nach dem Internet. Aktualisierungen für eine Kunstvermittlung am Bild. kopaed.

Seemann, M. (2014). Das neue Spiel. Strategien für die Welt nach dem digitalen Kontrollverlust. Orange Press.

Shifman, L. (2012). An anatomy of a YouTube meme. New Media and Society, $14(2), 115-137$.

Shifman, L. (2014a). Memes in digital culture. MIT Press.

Shifman, L. (2014b). Meme. Kunst, Kultur und Politik im digitalen Zeitalter. Suhrkamp.

Stalder, F. (2017). Kultur der Digitalität (2nd ed.). Suhrkamp.

Steyerl, H. (2016). A Sea of Data: Apophenia and Pattern (Mis)Recognition. e-flux Journal, 72. http://worker01.e-flux.com/pdf/article_9006382.pdf.

Thelwall, M., \& Shifman, L. (2009). Assessing global diffusion with Web memetics: The spread and evolution of a popular joke. Journal of the American Society for Information Science and Technology, 60(12), 2567-2576. 
Open Access This chapter is licensed under the terms of the Creative Commons Attribution 4.0 International License (http://creativecommons.org/licenses/ by $/ 4.0 /$ ), which permits use, sharing, adaptation, distribution and reproduction in any medium or format, as long as you give appropriate credit to the original author(s) and the source, provide a link to the Creative Commons license and indicate if changes were made.

The images or other third party material in this chapter are included in the chapter's Creative Commons license, unless indicated otherwise in a credit line to the material. If material is not included in the chapter's Creative Commons license and your intended use is not permitted by statutory regulation or exceeds the permitted use, you will need to obtain permission directly from the copyright holder.

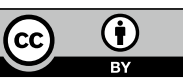

